\title{
Efficacy of Escitalopram in Pain, Anxiety, and Depressive Symptoms of Patients with Breast Cancer: A Randomized Single-Blind Controlled Trial
}

\author{
Novin Nikbakhsh ${ }^{1}$, Zohreh Hasani ${ }^{2}$, Alireza Azizi ${ }^{3}$, Ebrahim Zabihi', Atefeh Ghanbari ${ }^{5}$, Razieh Salehian ${ }^{5}$ and \\ Sussan Moudi $6,{ }^{*}$ \\ 1 Professor of Surgery, Cancer Research Center, Health Research Institute, Babol University of Medical Sciences, Babol, Iran \\ 2 Department of General Practice, Faculty of Medicine, Babol University of Medical Sciences, Babol, Iran \\ 3 Assistant Professor in Clinical Psychology, Social Determinants of Health Research Center, Health Research Institute, Babol University of Medical Sciences, Babol, Iran \\ ${ }^{4}$ Associate Professor in Pharmacology and Toxicology, Cellular and Molecular Biology Research Center, Health Research Institute, Babol University of Medical \\ Sciences, Babol, Iran \\ ${ }^{5}$ Associate Professor in Psychiatry, Department of Psychiatry, School of Medicine, Iran University of Medical Sciences, Tehran, Iran \\ ${ }^{6}$ Associate Professor in Psychiatry, Social Determinants of Health Research Center, Health Research Institute, Babol University of Medical Sciences, Babol, Iran
}

* Corresponding author: Sussan Moudi, Social Determinants of Health Research Center, Health Research Institute, Babol University of Medical Sciences, Babol, Iran. Email: sussan.mouodi@gmail.com

Received 2020 February 02; Revised 2021 June 05; Accepted 2021 June 20.

\begin{abstract}
Background: Pain, anxiety, and depression are common but often neglected problems in patients with cancer.

Objectives: Considering the importance and impact of anxiety and depression as common psychiatric symptoms in people with cancer, the present study aimed to assess the effectiveness of escitalopram in the reduction of pain, anxiety, and depression in patients with breast cancer.

Methods: This single-blind controlled trial was conducted on 32 patients diagnosed with breast cancer who were referred for modified radical mastectomy (2018-2019). The intervention group received daily oral capsules containing 10 milligrams of escitalopram for four weeks, while the control group received placebo capsules containing starch on a daily basis. Hospital Anxiety and Depression Scale (HADS) and Visual Analogue Scale were administered to the patients at the commencement of the study and four weeks after the intervention. In addition, at baseline examination, personality factors were assessed by the NEO Five-Factor Inventory-3 questionnaire.

Results: Based on the results, the scores of HADS anxiety, total HADS, and pain reduced after the intervention in the case group; however, the HADS depression score demonstrated a slight increase. A significant difference was observed between the case and control groups for HADS anxiety score after the intervention $(\mathrm{P}=0.01)$. The correlation of personality characteristics with HADS anxiety and depression subscales pointed out a significant negative correlation between the HADS depression score and conscientiousness $(r=-0.40 ; P<0.05)$.

Conclusion: Due to minor side effects of escitalopram, this drug is suggested to be used for the reduction of anxiety symptoms and pain intensity in patients with breast cancer.
\end{abstract}

Keywords: Anxiety, Breast neoplasms, Depression, Pain

\section{Background}

Pain, anxiety, and depression are common but often neglected problems in patients with cancer $(1,2)$. Advancements in cancer treatment have enabled these patients to live longer (3), and half of those who are diagnosed with cancer can expect to survive for at least 10 years (4). This definition of cancer as a long-term condition highlights the importance of the management of psychiatric disorders in patients diagnosed with malignancies $(3,4)$. A systematic review of the prevalence of symptoms of depression and anxiety in long-term cancer survivors revealed the prevalence of depression $(21.0 \%)$ and anxiety $(21.0 \%)$ in these patients (5).

Breast cancer, which affects 2.09 million new cases and causes 627, 000 deaths annually, is recognized as the second most common malignancy and the fifth cause of cancer deaths worldwide (6). A review article demonstrated that this cancer is the first common cancer $(24.4 \%$ of all cancers with an age-standardized incidence rate of 23.1 per
100,000 population) and the leading cause of cancer deaths among Iranian women (7). A previous study in the north of Iran revealed that $50.0 \%$ and $32.0 \%$ of patients with newly-diagnosed breast cancer had mild or severe anxiety; and $52.5 \%$ and $28.1 \%$ of cases had mild or severe depression, respectively (8).

Under-recognition and mismanagement of pain, anxiety, and depression can deteriorate the quality of life, patient's adherence to treatment, and treatment costs in patients with cancer (4). Some evidence has evaluated the efficacy of different modalities in the treatment of anxiety, pain, and/or depression in patients with malignancy, including breast cancer, in recent years (9-12).

Escitalopram as one of the most specific selective serotonin reuptake inhibitors (SSRIs) is used for the treatment of depression and anxiety disorders (13). Despite its efficacy, tolerability, and long-term effects, very limited clinical trials are available regarding the exclusive use of escitalopram for the treatment of patients with breast cancer (14). 


\section{Objectives}

In light of the aforementioned issues, the present study aimed to assess the efficacy of this drug in the reduction of pain, anxiety, and depression symptoms in patients with breast cancer.

\section{Methods}

This single-blind randomized controlled trial was conducted on patients diagnosed with breast cancer who were referred for modified radical mastectomy to state hospitals in Babol, north of Iran, within six months (from 11/6/2018 to 5/5/2019). To find three units of difference in HADS scores of the two groups after the intervention, the sample size was estimated at 16 cases with the confidence level of $95 \%$ and the study power of $80 \%$.

The patients were selected via the convenience sampling method. The inclusion criteria entailed 1) a recent diagnosis of breast cancer, and 2) having anxiety and/or depression symptoms based on the Hospital Anxiety and Depression Scale. On the other hand, the exclusion criteria were the history of elevated mood, suicidal thoughts, mental retardation, dementia, and current substance dependency. Demographic characteristics, including age, gender, level of education, place of residence, occupational status, and marital status, as well as comorbid illnesses, such as diabetes mellitus, thyroid gland, and cardiovascular disorders, were collected at the baseline examination.

The participants were randomly assigned to two groups. All of the patients in these two groups were in stage III of breast cancer and were referred for modified radical mastectomy. The intervention group received daily oral capsules containing 10 milligrams of escitalopram for four weeks, while the control group received placebo capsules containing starch. Placebo and escitalopram were filled into capsules of the same color and smell to execute a single-blind design. Both the case and control groups had free psychiatric visits during the study whenever they needed to. Moreover, in case of pain, they could receive ibuprofen $200 \mathrm{mg}$ tablet up to three times a day. The patients were evaluated for primary research outcomes at the commencement of the study (before surgery) and four weeks after the surgery.

Primary outcomes were pain intensity, depression, and anxiety which were measured at the baseline examination and four weeks after the intervention. Pain intensity was measured by the Visual Analogue Scale (VAS); moreover, depression and anxiety were assessed using the Hospital Anxiety and Depression Scale (HADS). Furthermore, personality factors were assessed by the NEO FiveFactor Inventory-3 questionnaire. This 60-item questionnaire is used to assess the five main personality factors: neuroticism, extraversion, openness to experiences, agreeableness, and conscientiousness. The items were rated on a 5-point Likert scale ranging from strongly disagree to completely agree. People with a high score are prone to irrational beliefs, are less able to control their impulses, and are much less likely to cope with stress, as compared to others. The psychometric properties of the Persian version of this questionnaire have been approved in previous studies (15).

The VAS is one of the most widely used pain assessment instruments in the world. The scores of 13 indicate mild pain, 4-7 suggest moderate pain, and 8-10 signify severe pain (16). The HADS is a 14 -item questionnaire employed for the assessment of anxiety (7 items) and depression symptoms (7 items). For each item, the participants are asked to indicate which of the four options (rated from 3-0 score) describes how they have been feeling in the past week. The scores of 0-7 indicate the absence of clinical symptoms of anxiety or depression, 8-10 are suggestive of mild anxiety or depression, and 11-21 signify symptomatic anxiety or depression (8).

The patients were interviewed, and these questionnaires were completed by a trained medical student. The obtained data were analyzed in SPSS software (version 16) using T-test, Chi-Square, Pearson's correlation coefficient, and ANOVA repeated measure. A p-value less than 0.05 was considered statistically significant. The current research was approved by the Ethics Committee of Babol University of Medical Sciences (ID: IR.MUBABOL.HRI.REC.1397.152) and was registered on the website of Iranian Clinical Trials with IRCT approval number: IRCT20150630022991N14. The study protocol is available at https://en.irct.ir/ trial/34451.

\section{Results}

A total of 32 female patients admitted for mastectomy surgery within the age range of 35-68 years were recruited in the present study. Participant's information is presented in Figure 1. The mean age scores of the participants were reported as $50.2 \pm 9.4$ and $49.7 \pm 9.1$ years in the case and control group, respectively $(\mathrm{P}=0.879)$. A number of 22 subjects $(68.8 \%)$ were living in urban areas, 27 (84.4\%) cases had an educational level of primary to secondary school, 27 (84.4\%) subjects were married, and 30 (93.8\%) cases were housekeepers. Baseline demographic and clinical characteristics for the intervention and control groups are presented in Table 1. As illustrated in this table, these two groups had no significant difference in the baseline characteristics $(\mathrm{P}>0.05)$.

The HADS and pain score of the two groups before and after the intervention is displayed in Table 2. Based on this table, HADS anxiety, total HADS, and 


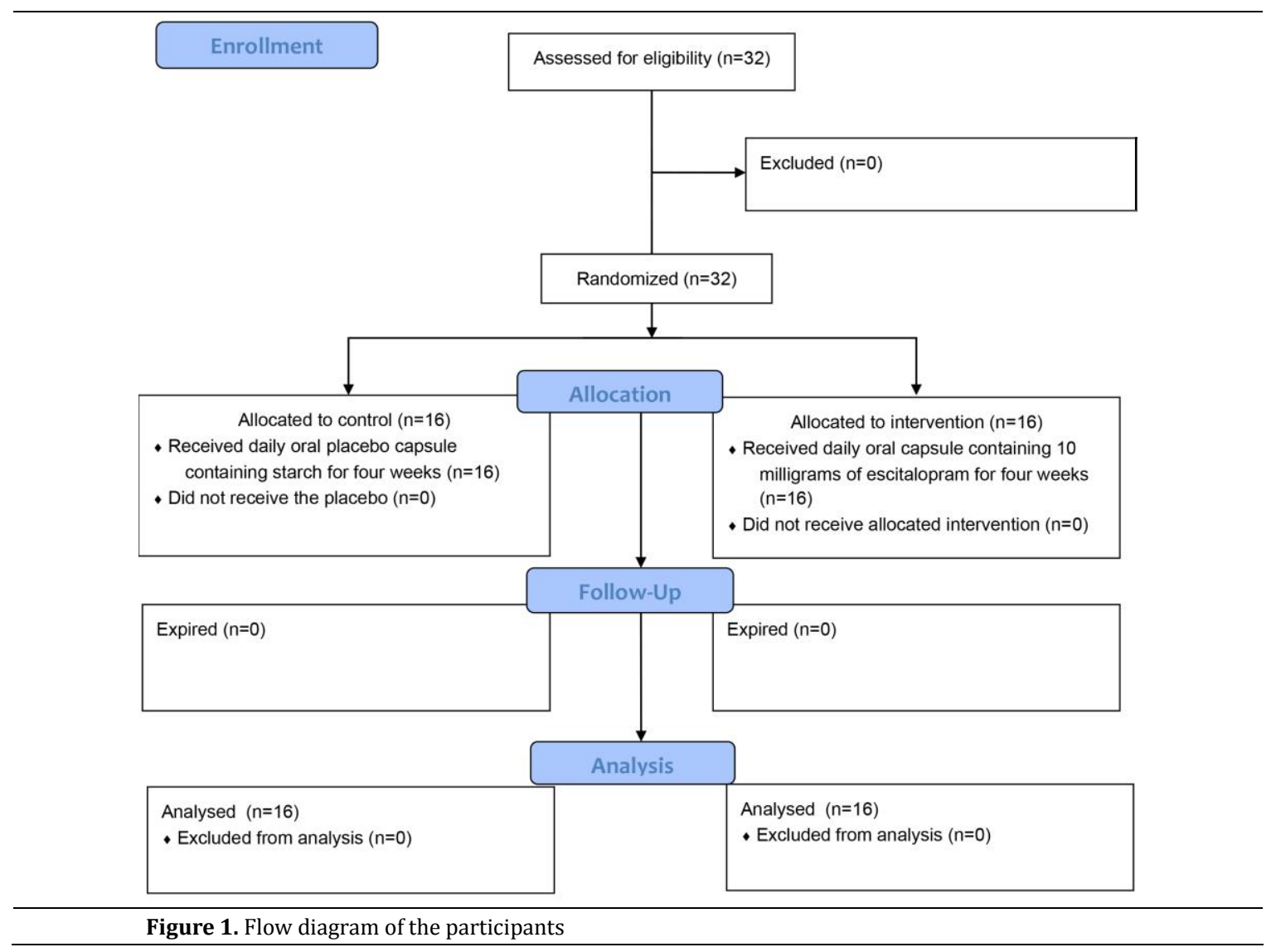

pain score reduced after the intervention in the case group; however, HADS depression score demonstrated a slight increase. In the control group, HADS depression and pain score decreased, and HADS anxiety and total HADS increased. A significant difference was detected between the case and control groups in HADS anxiety score after the intervention $(\mathrm{P}=0.01)$. No significant difference was observed between the case and control groups in HADS depression score $(\mathrm{P}=0.18)$, total HADS $(\mathrm{P}=0.06)$, and pain score $(\mathrm{P}=0.32)$. Personality factors of the two study groups at baseline examination are presented in Table 3. This table indicated that these two groups had no significant differences in the personality factors $(P>0.05)$, except for openness to experience $(\mathrm{P}=0.02)$. The correlation of personality factors with HADS anxiety, depression, and severity of pain in the intervention and control groups at baseline assessment and after the intervention is illustrated in Table 4 A significant negative correlation was observed between the HADS depression score and conscientiousness when post-intervention values were compared with the baseline measures $(r=-0.40$;

\begin{tabular}{|c|c|c|c|}
\hline Variable & $\begin{array}{c}\text { Intervention group } \\
\text { Number (Percent) } \\
n=16\end{array}$ & $\begin{array}{c}\text { Control group } \\
\text { Number (Percent) } \\
\mathbf{n}=16\end{array}$ & P-value \\
\hline Mean age (year) & $50.2 \pm 9.4$ & $49.7 \pm 9.1$ & 0.879 \\
\hline \multicolumn{4}{|l|}{ Living region } \\
\hline Urban & $13(81.25)$ & $9(56.25)$ & 0.127 \\
\hline Rural & $3(18.75)$ & $7(43.75)$ & \\
\hline \multicolumn{4}{|l|}{ Level of education } \\
\hline Illiterate & $2(12.50)$ & $1(6.25)$ & \\
\hline Primary to secondary school & $13(81.25)$ & $14(87.50)$ & 0.831 \\
\hline College education & $1(6.25)$ & $1(6.25)$ & \\
\hline \multicolumn{4}{|l|}{ Marital status } \\
\hline Single & $1(6.25)$ & $1(6.25)$ & \\
\hline Married & $14(87.50)$ & $13(81.25)$ & 0.386 \\
\hline Widowed & $0(0.00)$ & $2(12.50)$ & \\
\hline Divorced & $1(6.25)$ & $0(0.00)$ & \\
\hline \multicolumn{4}{|l|}{ Occupation } \\
\hline Housekeeping & $15(93.75)$ & 15 (93.75) & 0.999 \\
\hline others & $1(6.25)$ & $1(6.25)$ & \\
\hline
\end{tabular}


Nikbakhsh $N$ et al.

\begin{tabular}{|c|c|c|c|c|c|}
\hline \multirow[t]{2}{*}{ Variable } & \multicolumn{2}{|c|}{$\begin{array}{c}\text { Intervention group } \\
(\mathrm{n}=16)\end{array}$} & \multicolumn{2}{|c|}{$\begin{array}{c}\text { Control group } \\
(n=16)\end{array}$} & \multirow{2}{*}{$P$ value } \\
\hline & Mean & SD & Mean & SD & \\
\hline \multicolumn{6}{|l|}{ HADS anxiety score } \\
\hline Before the intervention & 10.93 & 3.58 & 7.56 & 2.60 & \multirow{2}{*}{0.01} \\
\hline After the intervention & 6.50 & 2.12 & 8.56 & 2.50 & \\
\hline \multicolumn{6}{|l|}{ HADS depression score } \\
\hline Before the intervention & 11.93 & 2.61 & 11.68 & 2.33 & \multirow{2}{*}{0.18} \\
\hline After the intervention & 12.25 & 2.08 & 11.56 & 2.60 & \\
\hline \multicolumn{6}{|l|}{ Total HADS score } \\
\hline Before the intervention & 22.87 & 4.92 & 19.25 & 3.60 & \multirow[b]{2}{*}{0.06} \\
\hline After the intervention & 18.75 & 2.59 & 20.12 & 3.84 & \\
\hline \multicolumn{6}{|l|}{ Pain Score } \\
\hline Before the intervention & 4.50 & 2.44 & 4.00 & 1.89 & \multirow{2}{*}{0.32} \\
\hline After the intervention & 2.93 & 2.51 & 2.18 & 1.55 & \\
\hline
\end{tabular}

HADS: Hospital Anxiety and Depression Scale

\begin{tabular}{|c|c|c|c|}
\hline Personality factors & $\begin{array}{c}\text { Intervention group }(n=16) \\
\text { Mean } \pm S D\end{array}$ & $\begin{array}{c}\text { Control group }(n=16) \\
\text { Mean } \pm \text { SD }\end{array}$ & P-value \\
\hline Neuroticism & $39.06 \pm 6.28$ & $39.58 \pm 7.16$ & 0.52 \\
\hline Extraversion & $45.50 \pm 3.70$ & $47.06 \pm 4.83$ & 0.31 \\
\hline Openness to experiences & $46.87 \pm 3.20$ & $47.06 \pm 4.68$ & 0.02 \\
\hline Agreeableness & $44.81 \pm 3.79$ & $45.50 \pm 4.72$ & 0.38 \\
\hline Conscientiousness & $47.12 \pm 2.44$ & $46.31 \pm 3.21$ & 0.18 \\
\hline
\end{tabular}

\begin{tabular}{|c|c|c|c|c|c|c|c|c|c|c|c|c|c|c|c|c|c|c|}
\hline \multirow[b]{3}{*}{$\begin{array}{l}\text { Personality } \\
\text { characteristics }\end{array}$} & \multicolumn{6}{|c|}{ HADS-anxiety } & \multicolumn{6}{|c|}{ HADS-depression } & \multicolumn{6}{|c|}{ Severity of pain } \\
\hline & \multicolumn{2}{|c|}{$\begin{array}{l}\text { Intervention } \\
\text { group }\end{array}$} & \multicolumn{2}{|c|}{ Control group } & \multicolumn{2}{|c|}{ Total } & \multicolumn{2}{|c|}{$\begin{array}{l}\text { Intervention } \\
\text { group }\end{array}$} & \multicolumn{2}{|c|}{ Control group } & \multicolumn{2}{|c|}{ Total } & \multicolumn{2}{|c|}{$\begin{array}{l}\text { Intervention } \\
\text { group }\end{array}$} & \multicolumn{2}{|c|}{ Control group } & \multicolumn{2}{|c|}{ Total } \\
\hline & 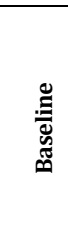 & 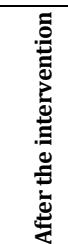 & 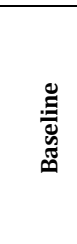 & 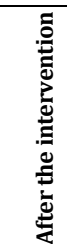 & 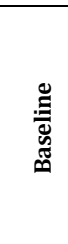 & 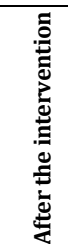 & 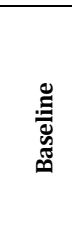 & 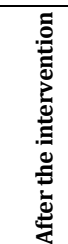 & 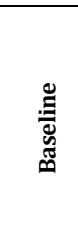 & 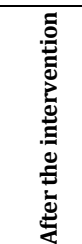 & 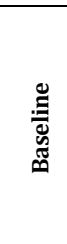 & 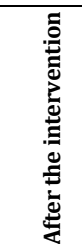 & 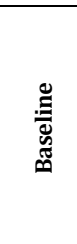 & 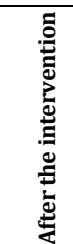 & 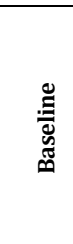 & 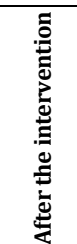 & 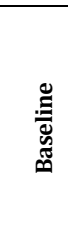 & 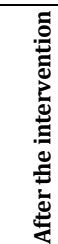 \\
\hline Neuroticism & -0.15 & -0.19 & 0.11 & 0.16 & -0.05 & 0.02 & -0.01 & 0.21 & -0.15 & -0.26 & -0.08 & -0.07 & -0.14 & 0.05 & 0.41 & 0.01 & 0.11 & 0.03 \\
\hline Extraversion & -0.20 & -0.26 & -0.13 & 0.04 & -0.22 & 0.01 & 0.32 & 0.41 & -0.41 & -0.44 & -0.08 & -0.14 & -0.22 & -0.20 & -0.26 & 0.05 & -0.25 & 0.01 \\
\hline $\begin{array}{l}\text { Openness to } \\
\text { experiences }\end{array}$ & 0.01 & -0.28 & $-0.50^{*}$ & -0.30 & -0.21 & -0.25 & $0.53^{*}$ & 0.48 & -0.10 & -0.18 & 0.16 & -0.04 & -0.49 & -0.11 & -0.36 & -0.09 & -0.40 & -0.09 \\
\hline Agreeableness & -0.46 & -0.44 & 0.14 & -0.06 & -0.19 & -0.16 & -0.01 & -0.22 & -0.36 & -0.37 & -0.19 & -0.03 & -0.29 & 0.08 & 0.15 & 0.26 & -0.08 & 0.21 \\
\hline Conscientiousness & -0.31 & -0.15 & 0.08 & 0.06 & -0.02 & -0.07 & 0.08 & -0.22 & -0.48 & $-0.55^{*}$ & -0.20 & $-0.40^{*}$ & -0.16 & 0.02 & -0.07 & -0.02 & -0.09 & -0.03 \\
\hline
\end{tabular}

$\mathrm{P}<0.05)$. The patients receiving escitalopram reported no serious drug side effects following the intervention.

\section{Discussion}

As evidenced by the results of the present study, escitalopram significantly reduced the anxiety symptoms in patients with breast cancer; however, its effect on depression symptoms was not significant. Moreover, although the intensity of pain decreased in both groups after four weeks, the difference between the intervention and control groups was not significant. Furthermore, no serious adverse side-effect was reported in patients who received this medication. Lydiatt et al. suggested that preventive use of escitalopram could reduce the risk of depression symptoms by more than $50 \%$ in nondepressed patients treated for head and neck cancers
(17). In the same context, Schillani et al. reported that the use of SSRIs could be effective in palliative care of patients with cancer. It not only relieves depression symptoms but also improves mental adaptation to cancer (18).

In addition, a significant negative correlation was detected between the HADS depression score and conscientiousness; and other personality characteristics had no significant correlation with HADS anxiety, depression, and pain intensity after the intervention. In contrast with the result of the present research, Chen et al. assessed the effect of personality traits on anxiety in patients with primary glaucoma and concluded that neuroticism was positively correlated with anxiety. Moreover, they reported that openness, conscientiousness, agreeableness, and extraversion had a significant negative correlation with anxiety (19). Kaplan et al. assessed the correlation of social anxiety with 
personality traits in a study conducted on 1,200 subjects and concluded that individuals with higher extraversion and less neuroticism reported less social anxiety. They also found that social anxiety was negatively correlated with openness, conscientiousness, and agreeableness (20). Along the same lines, Bienvenu et al. concluded that higher neuroticism could predict the incidence of anxiety and depression symptoms. They believe that depression, general anxiety, and neuroticism might have common genetic factors that are initially manifested by neurotic presentations, and consequently, a complete syndrome of general anxiety and depression occurs (21). In their metaanalysis study, Malouff et al. reported that patients with anxiety or depression had a higher degree of neuroticism and lower degrees of extraversion, agreeableness, and conscientiousness; nonetheless, this correlation was not observed with openness (22). Schrier reported that people with anxiety or depression symptoms might typically have higher neuroticism and extraversion, as well as lower agreeableness and conscientiousness (23).

This discrepancy between the results of the present study and those obtained in the aforementioned articles can be attributed to the small sample size of the research, study duration, or assessment tools (20). We used the HADS questionnaire for the assessment of anxiety and depression, and we might have had different results if we had examined the patients through a structured interview. A variety of factors affect the development of depression and anxiety in people with cancer. In general, this considerable disparity in the results of different studies can be justified by the following factors: individual characteristics (including age, gender, ethnicity, marital status, sexuality, disability, religion, biological factors, and comorbid disorders), sociodemographic factors (such as level of education, occupation, household income, social support, and health care system), characteristics of cancer (such as stage, grade, type of cancer, symptoms, curability, and recurrence), previous psychological factors, and cancer treatment aspects (1).

Pain intensity had no significant correlation with personality characteristics. Contrary to the findings of the current study, Naylor et al. detected a significant correlation between conscientiousness and chronic pain (24). Pour Mozaffari et al. pointed to a significant association of severe pain, neuroticism, social support, and strategies for coping with functional disability in patients with rheumatoid arthritis (25). Jalilvand Qazvini et al. represented that people with higher extraversion had a positive attitude, passion, and higher involvement in activities; moreover, they are interested in interacting more with others which increases their capacity to tolerate severe pain. Agreeable people with chronic pain who experience stressful events and negative emotions are expected to cope much better with severe pain regardless of levels of stress. It has been demonstrated that people with higher conscientiousness are less depressed, less fearful of pain, and more qualified to deal with pain (26). This difference might be due to the measurement tool. In the current study, the pain intensity was assessed by VAS which has been represented as the most common measure for the assessment of pain intensity in cancer research (27). The patients who are diagnosed with cancer might need to be visited medically for different purposes. The questionnaires used for the assessment of symptoms and treatment management of these patients should be specific and not time-consuming (28).

Among the notable limitations of this study, we can refer to the small sample size and short duration of follow-up. Therefore, it is recommended to conduct a larger study with longer duration of followup to compare the efficacy of escitalopram with other antidepressants.

\section{Conclusion}

Due to the minor side effects of escitalopram, this drug is suggested in patients with breast cancer. Since the effect of this medication is not significantly correlated with personality characteristics, except conscientiousness, it can be used for a wide range of patients without any limitation.

\section{Footnotes}

Authors' contribution: NN, EZ, ZH, AA, and SM contributed to the conception and design, as well as the acquisition, analysis, and interpretation of data. SM drafted the article. All authors have read the manuscript, revised it critically for important intellectual content, and approved the final version of the article to be published.

Conflicts of Interest: The authors declare that they have no conflict of interest.

Ethical Approval: The present study was approved by the Ethics Committee of Babol University of Medical Sciences (ID: IR.MUBABOL.HRI.REC.1397.152). All participants provided a written informed consent form to participate in the research.

Funding/Support: This research project was supported by the Research University Grant (Babol University of Medical Sciences; Grant number: 9706012). Hereby, the financial support of Babol University of Medical Sciences, Iran, is appreciated.

Informed consent: All participants were informed of personal characteristics or clinical details to be published in this study.

\section{References}

1. Niedzwiedz CL, Knifton L, Robb KA, Katikireddi SV, Smith DJ. Depression and anxiety among people living with and beyond 
cancer: a growing clinical and research priority. BMC Cancer. 2019;19(1):943. doi: 10.1186/s12885-019-6181-4. [PubMed: 31604468].

2. Wondimagegnehu A, Abebe W, Abraha A, Teferra S. Depression and social support among breast cancer patients in Addis Ababa, Ethiopia. BMC Cancer. 2019;19(1):836. doi: 10.1186/s12885-019-6007-4. [PubMed: 31455282].

3. Yi JC, Syrjala KL. Anxiety and depression in cancer survivors. Med Clin North Am. 2017;101(6):1099-113. doi: 10.1016/ j.mcna.2017.06.005. [PubMed: 28992857].

4. Pitman A, Suleman S, Hyde N, Hodgkiss A. Depression and anxiety in patients with cancer. BMJ. 2018;361:k1415. doi: 10.1136/bmj.k1415. [PubMed: 29695476].

5. Brandenbarg D, Maass S, Geerse OP, Stegmann ME, Handberg C, Schroevers MJ, et al. A systematic review on the prevalence of symptoms of depression, anxiety and distress in long-term cancer survivors: implications for primary care. Eur J Cancer Care (Engl). 2019;28(3):e13086. doi: 10.1111/ecc.13086. [PubMed: 31087398].

6. World Health Organization. Cancer key facts. Geneva: World Health Organization; 2018.

7. Farhood B, Geraily G, Alizadeh A. Incidence and mortality of various cancers in Iran and compare to other countries: a review article. Iran J Public Health. 2018;47(3):309-16. [PubMed: 29845017].

8. Nikbakhsh N, Moudi S, Abbasian S, Khafri S. Prevalence of depression and anxiety among cancer patients. Caspian J Intern Med. 2014;5(3):167-70. [PubMed: 25202445].

9. Busby J, Mills K, Zhang SD, Liberante FG, Cardwell CR. Selective serotonin reuptake inhibitor use and breast cancer survival: a population-based cohort study. Breast Cancer Res. 2018;20(1):4. doi: 10.1186/s13058-017-0928-0. [PubMed: 29351761].

10. Ahmed E. Antidepressants in patients with advanced cancer: when they're warranted and how to choose therapy. Oncology (Williston Park). 2019;33(2):62-8. [PubMed: 30784031].

11. Desautels C, Savard J, Ivers H, Savard MH, Caplette-Gingras A. Treatment of depression symptoms in patients with breast cancer: a randomized controlled trial comparing cognitive therapy and bright light therapy. Health Psychol. 2018;37(1):113. doi: 10.1037/hea0000539. [PubMed: 29172605].

12. Li M, Kennedy EB, Byrne N, Gérin-Lajoie C, Katz MR, Keshavarz $\mathrm{H}$, et al. Management of depression in patients with cancer: a clinical practice guideline. J Oncol Pract. 2016;12(8):747-56. doi: 10.1200/JOP.2016.011072. [PubMed: 27382000].

13. Kirino E. Escitalopram for the management of major depression disorder: a review of its efficacy, safety, and patient acceptability. Patient Prefer Adherence. 2012;6:853-61. doi: 10.2147/PPA.S22495. [PubMed: 23271894].

14. Park HY, Lee BJ, Kim JH, Bae JN, Hahm BJ. Rapid improvement of depression and quality of life with escitalopram treatment in outpatients with breast cancer: a 12-week, open-label prospective trial. Prog Neuropsychopharmacol Biol Psychiatry. 2012;36(2):318-23. doi: 10.1016/j.pnpbp.2011.11.010. [PubMed: 22142651].

15. Azkhosh M, Asgari A. Five factor model in Iranian culture: a psychometrics analysis of NEO-five factor inventory (NEOFFI). Int J India Psychol. 2014;1(4):78-101.

16. Nazemzadeh M, Jalalodini A, Rezvani M, Yousefian N, Poornamdar Z, Ghalge M. The effect of foot reflexology massage on pain intensity in patients with chronic low back pain visited to physical therapy unit in Baghiathallah hospital in Tehran. Complement Med J Facul Nurs Midwifery. 2012;2(3):1-8.

17. Lydiatt WM, Bessette D, Schmid KK, Sayles H, Burke WJ. Prevention of depression with escitalopram in patients undergoing treatment for head and neck cancer: randomized, double-blind, placebo-controlled clinical trial. JAMA Otolaryngol Head Neck Surg. 2013;139(7):678-86. doi: 10.1001/jamaoto.2013.3371. [PubMed: 23788218].

18. Schillani G, Capozzo MA, Era D, De Vanna M, Grassi L, Conte $\mathrm{MA}$, et al. Pharmacogenetics of escitalopram and mental adaptation to cancer in palliative care: report of 18 cases. Tumori. 2011;97(3):358-61. doi: 10.1700/912.10034. [PubMed: 21789016].

19. Chen J, Lin ZN, Tao YT, Zhao QN, Li Q, Yang H, et al. Influences of personality characteristics and coping modes on anxiety in primary glaucoma patients. Int J Ophthalmol. 2019;12(7): 1163-9. doi: 10.18240/ijo.2019.07.18. [PubMed: 31341809].

20. Kaplan SC, Levinson CA, Rodebaugh TL, Menatti A, Weeks JW. Social anxiety and the Big Five personality traits: the interactive relationship of trust and openness. Cogn Behav Ther 2015;44(3):212-22. doi: 10.1080/16506073.2015.1008032. [PubMed: 25705989].

21. Bienvenu OJ, Samuels JF, Costa PT, Reti IM, Eaton WW, Nestadt G. Anxiety and depression disorders and the five-factor model of personality: a higher-and lower-order personality trait investigation in a community sample. Depress Anxiety. 2004;20(2):92-7. doi: 10.1002/da.20026. [PubMed: 15390211].

22. Malouff JM, Thorsteinsson EB, Schutte N. The relationship between the five-factor model of personality and symptoms of clinical disorders: a meta-analysis. J Psychopathol Behav Assess. 2005;27(2):101-14. doi: 10.1007/s10862-005-5384-y.

23. Schrier AC, de Wit MA, Krol A, Fassaert TJ, Verhoeff AP, Kupka RW, et al. Similar associations between personality dimensions and anxiety or depression disorders in a population study of Turkish-Dutch, Moroccan-Dutch, and native Dutch subjects. J Nerv Ment Dis. 2013;201(5):421-8. doi: 10.1097/NMD.0b013e31828e110d. [PubMed: 23595096].

24. Naylor B, Boag S, Gustin SM. New evidence for a pain personality? A critical review of the last 120 years of pain and personality. Scand J Pain. 2017;17:58-67. doi: 10.1016/j.sjpain.2017.07.011. [PubMed: 28850375].

25. Davoodi I, Zargar Y, Mozafari Pour E, Nargesi F, Mola K. The relationship between pain catastrophizing, social support, pain-related anxiety, coping strategies and neuroticism, with functional disability in rheumatic patients. Quart $J$ Health Psychol. 2012;1(1):54-67.

26. Qazvini SJ, Kiapei FH, Mirzaian B. Evaluating the relationship between personality traits, coping strategies and pain catastrophizing in patients with chronic pain. Dis Diagn. 2017;6(2):1-3.

27. Hjermstad MJ, Fayers PM, Haugen DF, Caraceni A, Hanks GW, Loge $\mathrm{JH}$, et al. Studies comparing numerical rating scales, verbal rating scales, and visual analogue scales for assessment of pain intensity in adults: a systematic literature review. J Pain Symptom Manage. 2011;41(6):1073-93. doi: 10.1016/j. jpainsymman.2010.08.016. [PubMed: 21621130].

28. Stover AM, Basch EM. The potential role of symptom questionnaires in palliative and supportive cancer care delivery. Curr Oncol Rep. 2017;19(2):12. doi: 10.1007/s11912017-0571-z. [PubMed: 28220450]. 